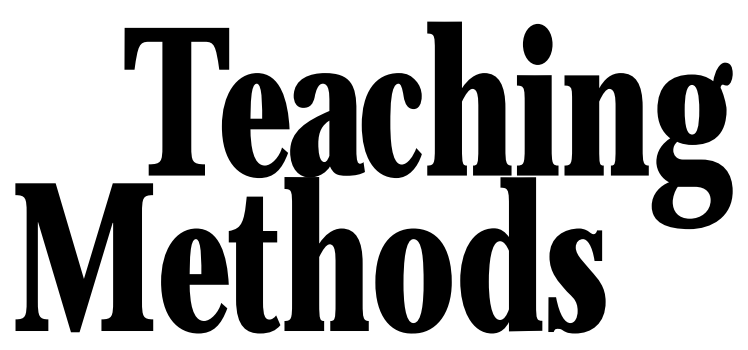

\section{Can Computer- assisted Instruction Be Used by Students for Woody Plant Identification?}

\author{
Anthony W. Kahtz
}

Additional index words. field dependence, cognitive learning styles, horticulture education

SummaRY. The cognitive learning style theory of field dependence and independence was used to examine the academic achievement of students using a computer assisted instruction (CAI) program in a woody plant identification course. The $G$ roup E mbedded Figures Test (GEFT) was used to determine the students' level of field dependence and independence. Students were blocked and randomly assigned to experimental or control groups. Participants in the experimental group used a nonlinear drill and tutorial type of CAI program as a partial laboratory substitute. The CAI program had no influence relative to traditional laboratories upon either field dependent or field independent students' long term memory of course material. $\mathrm{H}$ owever, the CAI program was of equal benefit to field dependent and independent students' academic achievement. $Q$ ualitative interviews

Curator of horticulture, Chicago Zoological Society Brookfield Zoo, Brookfield, IL 60513.

The cost of publishing this paper was defrayed in part by the payment of page charges. U nder postal regulations, this paper therefore must be hereby marked advertisement solely to indicate this fact. were also conducted to assess the effect of the CAI program. D ata indicated that field dependent students benefited from the CAI program as a presentation source of recall cues in the reviewing of course material, but not for the initial acquisition of knowledge. Field independent students may be able to use the CAI program to initially acquire knowledge, but its best usage may be as a method of presenting recall cues to refresh their memory. These results showed that the CAI program could be used as a partial laboratory substitute for traditional woody plant identification laboratories with no adverse effect upon student academic achievement, regardless of their level of field dependency.

W oody plant identification is a highly visual, handson area of study. Students must learn a variety of featuresto correctly identify a plant at different times of the year. Subtle variances in each plant'scharacteristics addsto the difficulty of learning the information. Woody plant materials need to be presented on a repetitive basis for students to learn, automatically recall and correctly identify.

Thetimehonored instructional methods of woody plant identification are outdoor laboratories supplemented with cut indoor specimens. Outdoor laboratories aretimeconsuming and areprimarilyused to present new plantsto thestudentseach week, with continuing review of previous material. O utdoor laboratories are also subject to inclement weather and daylight hours. C utindoor specimensrequirelaboratory space, need frequent refreshing and require a great amount of time to collect. Furthermore, thesetraditional instructional methodsmaynotprovidean optimal learning environment for all students.

$\mathrm{N}$ ot all students learn in the same manner. I ndividuality plays a major role in how a student learns, and certain patterns of learning behavior may be observed with each individual (Cox et al., 1988). Furthermore, cognitivelearning styles are critical in how students respond to information. $U$ Itimately, the primary objective of education is to enhance the learning and development of all students through their unique differences.

Cognitivelearning styleshavegreat implicationsfor the educational process (Sternberg and G rigorenko, 1997) and are best described asthemodesin which students approach, acquire, organize and process information. They are the consistent manner in which an individual perceives and carries out intellectual activities and they include areas such as how a student memorizes and retrieves information (Witkin et al., 1971; Witkin and Goodenough, 1981). These cognitive learning style differences are important for educators to understand and act upon in this age of technological advancement when instructional delivery formats are rapidly changing (Bork, 1997).

The use of computer assisted instruction (CAI) programsin higher education coursework has received much attention in the past several years. CAI has thepotential to facilitateand supplement individual learning in a manner unlike any other educational media (Piemme, 1988). In the early 1990s, the field of agriculture, which includes horticulture, began to develop and implement more CAI programs to be used in coursework (Johnson and Oltenacu, 1991).

CAI may be a viable instructional method for teaching woody plant identification to students(Shaw, 1993; Seiler et al., 1996) and can provide students the unlimited ability to see and review plant specimens at their convenience. Students could al so view a greater number of plants in less time than in a traditional laboratory setting. Research has shown that drill and tutorial types of CAI programs have great potential in presenting information (Alessi and Trollip, 1991).

U nfortunately, and unintentionally, many CAI programshaveneglected cognitive learning styles and the processes of how students learn (Pillay, 1998). Clearly, the danger is in assuming that student learning, regardless of cognitivelearning style, will beenhanced by CAI. The recognition that individualshavediffering cognitivelearning styles 
has become an important factor in the development and usage of CAI programs (Billings and Cobb, 1992; Pillay, 1998). Further examination of how information is delivered and processed in CAI programs needs to be undertaken in order to ensure that students of various cognitive learning styles are receiving the full benefits of such programs (H edberg et al., 1993; Rossand Schulz, 1999).

Theobjectives of thisstudy were to investigate differences between theacademic achievement of field dependent and field independent students with and without the use of a CAI program on woody plant identification. TheCAI program was used in this study as a required partial substitution for traditional laboratory instructional delivery and as an elective supplement to lectures.

\section{Field dependence and independence}

Among the most substantiated of cognitive learning style theories are Kolb's (1984) experiential learning theory, Gregorc's (1982) learning style delineator and thetheory of field dependence and independence (Witkin et al., 1971). Of all these theories, field dependence and independence is one of themost heavily researched (Witkin and Goodenough, 1981). In addition, the field dependent and independent cognitive learning style may provide the greatest amount of potential for exploring educational issues (Luk, 1998).

Field dependence and independence is typically assessed through the group embedded figures test (GEFT). $\mathrm{H}$ ow a person responds to the GEFT clearly indicates their general tendencies in learning, perceiving, and understanding theworld (Witkin et al., 1971). The GEFT is a visual test whereby, the individual is shown a simple geometric figure, and is then shown a more complex geometric figure that has within it the simple form. The object is for the individual to find, or disembed, the simplegeometric figure from within the more complex geometric figure. The student's ability to disembed the simple figure without being distracted by the complex figure indicates the degree to which the individual is field dependent or field independent. The GEFT has a total of 18 problems, with each solved correctly scored as 1 = incorrect or unsolved problems are scored as 0 (Witkin et al., 1971). A high score is judged as being field independent; the national average score on the GEFT is 13.2 .

An examination of the literature of field dependence and independence revealsthefollowing generalizations. Field dependent students rely mostly upon external guidance for learning and take the organization of a field of knowledge as a given; they favor a structured learning environment and are motivated to demonstrate or explain the concept to be learned and its significance to other people. Furthermore, field dependent learners are more deliberate and passive when learning and do not thrive on classroom competition (Witkin et al., 1977).

Field independent individualstake a more individualized approach when engaging in cognitive activitiesand they structureinformation according to their needs. These students prefer to analyze and discover how a concept is useful to them. Field independent students are also likely to use mnemonic devices for information storage and recall. Field independents are highly active processors of acquiring information and enjoy competition in learning environments. (Abouserie et al., 1992; Burwell, 1991; Witkin et al., 1977). In addition, field independent students typically have better analytical and restructuring skills than field dependent students (Witkin et al., 1977). Readers interested in a detailed description of field dependence and independence are directed to Wapner and Demick (1991), Witkin and Goodenough (1981), Witkin et al. (1977), and Witkin et al. (1971).

\section{Materials and methods}

Description of cal program. Academic achievement differences were studied between field dependent and independent students who used a CAI program called UIPLANTS. The program was designed to assist students in identifying and learning ornamental and cultural requirements of landscapetrees and shrubs. U I PLAN TShas $>7000$ color imageswith accompanying text descriptions. Visual images of each plant included leaf, bud, stem, bark, flower, fruit, habit and fall color characteristics in addition to cultural requirements. Special features included customized slide shows, side-by-side image comparisons and a self quiz.

The slide show feature allows students to view all of the images of any selected genus or group of plants with- out the text. I mages of the selected features of each plant can be presented in theorder that thestudent desireswith a variable image display time. The sideby-sidecomparison allowsadjacent viewing of any two images within the program. I n the self quiz, students may test their knowledge by typing in the name of the image that is presented on the computer screen. Thestudentscan navigatebackwards, forwardsand randomly through the program. The program is a nonlinear, drill and tutorial type of CAI package.

SAMPLE. The 1996 and 1997 fall semester classes of a woody plant identification, cultureand usage coursewere selected for evaluation over the entire fall semester. D ue to different quiz material, the two classes were evaluated as separate experiments. Classification of the students' cognitive learning style wasdetermined by the GEFT (Witkin et al., 1971), which was administered on the first day of class to 56 students in 1996 and 63 students in 1997. The studentswereblocked by cognitivelearning style and randomly selected for either the treatment or control groups.

All subjects attended lectures, labs and had a required text book availableto them. The treatment group used the UIPLANT S computer program for the first 30 min of a 2 -h lab onceaweek. The last $1 \mathrm{~h}$ and 30 min were spent in a traditional woody plant identification classsetting. Thetreatment group could also use the CAI program at any other time during the day, evening or weekend. Furthermore, it was entirely up to the participating students to use the program features as they saw fit. The control group received the traditional instructional methods for the course and did not have access to the UIPLANTS program. All of the students were volunteers who had the option of not participating in the study. The students were free to exercise their nonparticipation option at any time during the research. These procedures were followed for both the 1996 and 1997 classes.

Student achievement. Students were expected to learn to identify 165 trees and shrubs, using a variety of plant features. In addition, they were also expected to learn the primary ornamental and cultural characteristics of approximately 300 plants over the duration of a semester. I dentification features were taught in a series of weekly laboratories which illustrated ornamen- 
tal and cultural characteristics in a slidelecture format. Student academic achievement was determined through a series of cumulative quizzes that covered the plant identification portion of thematerial. A pproximately threeweeks separated each quiz.

Data collected. D ata were gathered for each participating student on their GEFT scores, atest of prior knowledge, the amount of time each student in the experimental group used the CAI program outside of class, plant identification quiz scores and grade point average (GPA). After scoring of the GEFT, students who scored 14 and above were identified as field independent; those identified as field dependent scored 13 and below.

In an additional data analysis, studentswerequartiled with thosethat had GEFT scoresin thelower quartile being identified as field dependent and the students in the top quartile designated asfield independent. Studentswho comprised the middle $50 \%$ werefiltered out. This strategy examined students who exhibited the greatest tendencies of being either field dependent or field independent.

In a separate but concurrently running study, students were interviewed using qual itative research methodsconcerning field dependent and independent conceptualizations of how they preferred to learn (Kahtz and Kling, 1999). Results from that research will be used to aide in the interpretation of the quantitative results.

Three-way analysis of covariance ( $3 \times$ AN CO VA) was used to analyze the data (SPSS, 1997). U sing four cells for each year. The result was a $2 \times 2 \times 3$ (cognitivestyle[ field dependent vs. field independent] $\times$ treatment [experimental vs. control] $\times$ quiz [3 quiz scores] repeated measures research design. The students' GPA was obtained to control for ability and or motivation. Cognitive style and treatment were the independent variables. The quiz scores werethe dependent variable.

\section{Results and discussion}

Students demonstrated no significant level of prior knowledge of the course content in either the 1996 or 1997 classes. The amount of time each student utilized the CAI program outside of class had no significant effect upon their quiz scores(D atanot shown). H owever, asignificant effect of GPA did occur and it was used as the covariate in thisresearch to control for ability and or student motivation. Results were the same if a cutoff of 14 on the GEFT was used to describe the students as either field dependent or field independent or if the data were quartiled. D ue to the statistical levels of significance being identical for each year, only the 1997 class statistics are presented.

For both participating years, the main effect of quiz wassignificant at the $p<0.01$ level (Table 1$)$. For both years the main effects of cognitive style and treatment were nonsignificant as were the three-way interactions. All two-way interactionsfor both participating classes were also nonsignificant.

The predominance of field independent studentsin thisstudy (T able 2) isnot surprising sincecognitive learning styles may also play a role in college major selection (Witkin et al., 1977). Individuals who are field dependent generally will select disciplines that are socially oriented and in which analytical and restructuring abilities are not considered of great importance, for example, social work and education (Witkin and Goodenough, 1981). In contrast, field independent individuals are likely to select disciplines such as math and the sciences that require the use of analytical and restructuring skills.

Three-way AN COVA showed that the resulting mean quiz 3 scores for both years were significantly lower than quiz 1 and 2 scores (T able 2). This may be attributable to when quiz 3 was administered, which for both classes, was within 1 week after the students returned from a semester break. Given the drop in the quiz 3 means from quiz 1 and 2 it may be assumed that the CAI program had no differential influence upon field dependent or field independent students' long term memory.

The two-way and three-way interactions for either of the participating classes were not significant, indicating that the CAI program was of equal benefit to both field dependent and field independent students using the program (Table 1). Therefore, the recall cues students need to identify plant specimens on the quizzes may indeed be the same as those seen when the plants were initially introduced. Frank (1983) suggests that there is no difference between field dependent and field independent studentswhen theretrieval cueisthesameastheinformation stimuli at the initial presentation of material. This research demonstrated that the UIPLANTS program can successfully serve as a partial substitute for traditional woody plant identification laboratories with no detrimental effect on student achievement, regardless of cognitive learning style.

I fstudentsarelearning in amanner that is consistent with their cognitive learning style, their academic achievement can be influenced. Recent research has shown the following (Kahtz and Kling, 1999). Field dependent students preferred a discussion format in both laboratory and lecture and felt there was no additional benefit from using this nonlinear drill and tutorial type of program. H owever, they suggested that a more positive influence might occur if the program were more structured, or if structured guidance

Table 1. Effect of UIPLANTS computer assisted instruction program on field dependent and independent 1997 woody plant identification quiz scores.

\begin{tabular}{lcrrr}
\hline Source & df & $\begin{array}{c}\text { M ean } \\
\text { square }\end{array}$ & $\begin{array}{c}\mathbf{F} \\
\text { value }\end{array}$ & Significance \\
\hline Covariate & & & & \\
$\quad$ Grade point average & 1 & $14,218.24$ & 35.32 & $* *$ \\
M ain Effects & & & & \\
$\quad$ Cognitive style (CS) & 1 & 423.42 & 1.05 & NS \\
$\quad$ Treatment (T) & 1 & 834.03 & 2.07 & NS \\
$\quad$ Q uiz (Q) & 2 & 1225.10 & 13.40 & $* *$ \\
Two-way interaction & 1 & 1020.52 & 2.54 & NS \\
$\quad$ CS $\times$ T & 2 & 10.86 & 0.12 & NS \\
$\quad$ Q $\times$ CS & 2 & 45.99 & 0.50 & NS \\
$\quad$ Q $\times$ T & 2 & 112.75 & 1.23 & NS \\
Three-way interaction & & & \\
$\quad$ CS $\times$ T $\times$ Q & 116 & 91.40 & & \\
Error &
\end{tabular}

\footnotetext{
s, ${ }^{* * *} \mathrm{~N}$ onsignificant or significant at $\mathrm{P}=0.05$ or 0.01 , respectively.
} 
T able 2. Sample size, quiz mean and SD of 1997 field dependent and independent students participating in U I PL ANT S computer assisted instruction research.

\begin{tabular}{|c|c|c|c|c|c|c|c|}
\hline \multirow[b]{2}{*}{ Student } & \multirow[b]{2}{*}{$\mathbf{N}$} & \multicolumn{2}{|c|}{ Q uiz 1} & \multicolumn{2}{|c|}{ Q uiz 2} & \multicolumn{2}{|c|}{ Q uiz 3} \\
\hline & & M ean & SD & Mean & SD & Mean & SD \\
\hline \multicolumn{8}{|c|}{ Field dependent } \\
\hline Expt. & 8 & 93.52 & 6.12 & 95.45 & 6.56 & 74.56 & 15.06 \\
\hline Control & 11 & 76.64 & 16.12 & 71.93 & 21.82 & 55.17 & 27.49 \\
\hline \multicolumn{8}{|c|}{ Field independent } \\
\hline Expt. & 25 & 84.40 & 14.50 & 85.19 & 14.82 & 69.41 & 20.89 \\
\hline Control & 19 & 85.07 & 12.02 & 85.13 & 13.26 & 65.46 & 17.13 \\
\hline
\end{tabular}

were provided for them while using this CAI program. It may beconcluded that field dependent students do not believe they benefit from aCAI program, such as UIPLANTS, as compared to traditional woody plant identification laboratories. $\mathrm{H}$ owever, field dependent students realized the value of using UIPLANTS for review purposes, but not for the initial acquisition of knowledge. Abouserie et al. (1992) reported that students favored CAI as a supplemental form of educational media, but not as a substitute for other forms of instruction.

Field independent students preferred a traditional woody plant identification laboratory and lecture to using UIPLANTS. Although theyviewed this CAI program as a beneficial study tool, they viewed it as supplementary only. And, although field independent studentsare capable of providing their own structure, they felt that additional instructor-directed structuremay increase the program's utility for their learning. Although field independent students may use the program to initially acquire information, its best usage may be to present recall cues to refresh learning.

Based on similar responses from field dependent and independent students, one advantage of U IPLAN TS is its year-round versatility for study. The ability to view, for example, the leaves of a deciduous plant in winter may be useful for memory retention of thecourse material. In addition, access to thistype of information is unmatched during inclement weather. This CAI program wasdesigned to serveasasupplement to the traditional lecture and laboratory delivery of subject matter. Results revealed that thestudents agreed with the intended usage of U IPLANT S and that it did serve that purpose.

This study was a first step in attempting to assess the effect of such a CAl program. It is advantageous that this study took place over an entire semester and with two different intact classes. D ueto this, thelong term effects of using this CAI program could be examined in depth. The next step in examining this program would be to implement an even greater amount of CAl time usage by the students in an experimental group.

Structural computer design elements that affect the learning of students with different cognitive learning stylesneedsto beinvestigated further. It is important to investigate the instructional implementation of this type of CAI program into the visual environment of a woody plant identification course with students of varying cognitive learning styles. As technology continues to advance, educators must pursue ways to increase the effectiveness of CAI programsfor students of all cognitive learning styles.

\section{Literature cited}

Abouserie, R., D. M oss, and S. Barasi. 1992. Cognitive style, gender, attitude toward learning and academic achievement. Educ. Studies 18(2):151-160.

Alessi, S.M . and S.R. Trollip. 1991. Computerbased instruction: $M$ ethods and development. 2nd ed. Simon \& Schuster, Englewood Cliffs, N.J.

Billings, D.M . and K.L. Cobb. 1992. Effects of learning style preferences, attitude and gpa on learner achievement using computer assisted interactivevideodisc instruction. J. Computer Based Instr. 19(1):12-16

Bork, A. 1997. The future of computers and learning. T.H.E. J. 24(11):69-77.

Burwell, L.B. 1991. The interaction of learning styles with learner control treatments in an interactivevideodisclesson. Educ. T echnol. 31(3):3743.

Cox, D.E., E.K. Sproles, and G.B. Sproles. 1988. L earning style variationsbetween rural and urban students. Res. Rural Educ. 5:27-31.
Frank, B.M. 1983. Flexibility of information processing and the memory of field-independent and field-dependent learners. J. Res. Personality $17(1): 89-96$

Gregorc, A.F. 1982. An adult's guide to style. Gregorc Assoc., Columbia, Conn.

H edberg, J.G., B. H arper, and C. Brown. 1993. Reducing cognitive load in multimedia navigation. Austral. J. Educ. Technol. 9(2):157-181.

Johnson, P.J . and P.A O Itenacu. 1991. The use of computers to develop problem solving skillsin agriculture. J. Computer Based Instr. 18(4):135138.

Kahtz, A.W. and G.J. Kling. 1999. Field-dependent and field-independent conceptualisations of various instructional methods with an emphasis on cai: A qualitative analysis. Educ. Psychol. 19(4):413-428.

Kolb, D .A. 1984. L earning styleinventory: Technical manual. M CBear and Co., Boston, M ass.

Luk, S.C. 1998. Therelationship between cognitive style and academic achievement. Brit. J. of Educ. Technol. 29(2):137-147

Piemme, T.E. 1988. Computer-assisted learning and evaluation in medicine. J. Amer. M ed. Assn. 260(3):367-372.

Pillay, H . 1998. An investigation of the effect of individual cognitive preferences on learning through computer-based instruction. Educ. Psychol. 18(2):171-182.

Ross, J. and R. Schulz. 1999. Can computeraided instruction accommodate all learners equally? Brit. J. Educ. Technol. 30(1):5-24

Seiler, J.R., J.A. Peterson, C.D. T aylor, and P.P. Feret. 1996. A computer-based multimedia instruction program for woody plant identification. J. N atural Resource Life Sci. Educ. 26(2):129131.

Shaw, P.M. 1993. A low-cost interactive computer program for teaching landscape plant materials. H ortT echnology 3(3):351-354

SPSS. 1997. SPSS Base 7.5 for Windows. SPSS Inc., Chicago, III.

Sternberg, R.J . and E.L. Grigorenko. 1997. Are cognitive learning styles still in style? Amer. Psychol. 52(7):700-712.

Wapner, S. and J. Demick. 1991. Field dependence-independence cognitive style across the lifespan. Lawerence Erlbaum Assoc., H illsdale, N.J.

Witkin, H.A. and D.R. Goodenough. 1981. Cognitive styles: Essence and origins. Intl. U niv. Press, N ew York.

Witkin, H.A., C.A. M oore, D.R. Goodenough, and P.W. Cox. 1977. Field-dependent and fieldindependent cognitive styles and their educational implications. Rev. of Educ. Res. 47(1):164.

Witkin, H .A., P.K. O Itman, E. Raskin, and S.A. Karp. 1971. A manual for the embedded figures tests. Consulting Psychologists Press, Palo Alto, Calif. 